\title{
UJI KOMPARATIVE PENYUSUNAN ANGGARAN SATUAN KERJA PERANGKAT DAERAH (RKA-KPD) DINAS PEKERJAAN UMUM KABUPATEN PESISIR SELATAN
}

\author{
Ria Nurma Yunita, Febryandhie Ananda \\ STIE “KBP" Padang \\ (nurmayunitaria@yahoo.co.id) \\ (febryandhie@akbpstie.ac.id)
}

\begin{abstract}
ABSTRAK
Penyusunan anggaran Dinas Pekerjaan Umum Kabuaten Pesisir Selatan berpedoman kepada Renstra 2011-2015 serta Renja 2013 Dinas Pekerjaan Umum Kabupaten Pesisir Selatan yang tidak terlepas dari visi, misi Kabupaten Pesisir Selatan yang tertuang dalam Rencana Pembangunan Jangka Menengah Daerah (RPJMD). Penyusunan anggaran ini dimulai dari penyusunan strategi dan prioritas dengan memperhatikan (nilai organisasi, pengaruh lingkungan internal dan eksternal organisasi, analisis trategi dan pilihan, faktor kunci keberhasilan, formulasi perumusan tujuan), penentuan visi dan misi, penentuan tujuan dan sasaran, serta penentuan tugas dan fungsi organisasi. Dalam penyusunan anggaran Dinas Pekerjaan Umum Kabupaten pesisir Selatan menggunakan analisis SWOT yaitu menggunakan strategi Kekuatan (Strenght), Kelemahan (Weakness), Peluang (Opportunity), dan Ancaman (Threats).

Jenis data yang digunakan dalam penelitian ini adalah data primer dan sekunder, teknik pengumpulan data adalah penelitian keperpustakaan, dan penelitian lapangan (wawancara dan observasi). Sedangkan metode yang digunakan dalam penulisan adalah metode kualitatif deskriptif, yaitu mengumpulkan, menyusun, mengklasifikasikan, dan menganalisa data untuk memberikan gambaran dan jawaban yang jelas dan akurat dari perumusan masalah dan kemudian melakukan evaluasi terhadap data yang dikumpulkan tersebut dan menganalisis hubungannya dengan masalah yang dibahas.
\end{abstract}

Kata Kunci : Penyusunan Rencana Kerja dan Anggaran Satuan Kerja Perangkat Daerah (RKA-SKPD)

\section{PENDAHULUAN}

Era globalisasi merupakan sesuatu yang tidak dapat dihindari oleh masyarakat dunia. Bangsa Indonesia sebagai bagian masyarakat dunia memiliki kewajiban untuk serta terus menerus berpartisipasi dalam mewujudkan Pemerintah yang baik (good governance) termasuk di bidang pengelolaan keuangan daerah.
Pemerintah pusat memberikan kewenangan kepada pemerintah daerah untuk mengatur dan mengawasi sendiri urusan pemerintahn sesuai dengan Undang-Undang No. 32 Tahun 2004 tentang Pemerintah Daerah dan Undang - Undang No. 33 Tahun 2004 tentang Perimbangan Keuangan antara Pemerintah Pusat dan Pemerintah Daerah. Penyelenggaraan urusan 
pemerintah yang menjadi kewenangan daerah seperti yang disebutkan di atas didanai dari dan atas beban Anggaran Pendapatan dan Belanja Daerah (APBD), yang merupakan dasar pengelolaan Keuangan Daerah dalam masa satu tahun anggaran. Dalam Undang-Undang 17 Tahun 2003 tentang Keuangan Negara Pasal 19 (1) dan (2) menyebutkan bahwa, dalam rangka penyusunan RAPBD. Satuan Kerja Perangkat Daerah (SKPD) selaku pengguna anggaran menyusun rencana kerja dan anggaran (RKA-SKPD) dengan pendekatan berdasarkan prestasi kerja yang akan dicapai.

Dalam penyusunan Rencana Kerja dan Anggaran Satuan Kerja Perangkat Daerah (RKA-SKPD) diharapkan dapat menghasilkan output berupa pembangunan daerah yang merata dan berkelanjutan yang didasari oleh aspek transparansi dan partisipasi. Transparansi di bangun atas dasar kebebasan dalam memperoleh informasi, dan partisipasi diharapkan agar dapat mengikutsertakan masyarakat dalam pembuatan keputusan agar maksud dan tujuan tepat sasaran.

Menurut Sabeni (2001:39) "Anggaran merupakan jenis rencana yang menggambarkan rangkaian tindakan atau kegiatan yang dinyatakan dalam bentuk angka-angka rupiah untuk suatu jangka waktu tertentu. Anggaran juga dapat didefinisikan sebagai rencana keuangan periodik yang disusun berdasarkan program yang telah disahkan dan merupakan rencana tertulis mengenai kegiatan suatu organisasi yang dinyatakan secara kuantitatif dan umumnya dinyatakan dalam satuan moneter untuk jangka waktu tertentu. Perusahaan yang baik juga menggambarkan sistem anggaran yang baik pula. (Ananda, Putra and
Hendrastyo, 2017; Ananda and Zulvia, 2018)

Anggaran sektor publik merupakan perencanaan finansial tentang perkiraan pengeluaran dan penerimaan yang diharapkan terjadi di masa mendatang dengan melihat data yang diperoleh dari masa lalu sebagai acuan penetapan anggaran. Penganggaran sektor publik terkait dengan proses penentuan jumlah alokasi dana untuk tiap-tiap program dan aktivitas dalam satuan moneter. Proses penganggaran organisasi sektor publik dimulai ketika perumusan strategi dan perencanaan strategik telah selesai dilakukan. Tahap penganggaran menjadi sangat penting karena anggaran yang tidak efektif dan tidak berorientasi pada kinerja akan dapat menggagalkan perencanaan yang telah disusun. Sehingga untuk mencapai target dan perencanaan dimasa depan, maka penganggaran dapat disimpulkan sebagai managerial plan for action untuk memfasilitasi tercapainya tujuan organisasi.

Dinas Pekerjaan Umum Kabupaten Pesisir Selatan dalam hal ini berusaha menyesuaikan adanya perubahan-perubahan kondisi dan perkembangan dalam penyusunan anggaran dengan tidak mengabaikan visi dan misi nya sendiri agar maksud dan tujuan anggaran tepat pada sasaran, sehingga pembangunan dapat diakukan secara merata dan berkelanjutan.

Berdasarkan uraian di atas dan juga penelitian terdahulu yang dilakukan oleh Dewi (2012) dengan judul "Analisis Proses Penyusunan Anggaran Satuan Kerja Perangkat Daerah (RKA-SKPD) Dinas Pekerjaan Umum Kabupaten Deli Serdang" dengan hasil penelitian bahwa penyusunan RKA-SKPD Dinas Pekerjaan Umum Kabupaten Deli Serdang sesuai dengan visi dan misi 
Dinas Pekerjaan Umum Kabupaten Deli Serdang, maka penulis tertarik melakukan penelitian dalam bentuk skripsi dengan judul "Analisis Penyusunan Anggaran Satuan Kerja Perangkat Daerah (RKA-SKPD) Dinas Pekerjaan Umum Kabupaten Pesisir Selatan".

Berdasarkan latar belakang masalah yang telah dikemukakan di atas maka penulis merumuskan masalah penelitian ini adalah: bagaimana penyusunan Anggaran Satuan Kerja Perangkat Daerah (RKASKPD) Dinas Pekerjaan Umum Kabupaten Pesisir Selatan.

\section{TINJAUAN PUSTAKA DAN HIPOTESIS \\ Proses Penyusunan Rencana Kerja dan Anggaran Satuan Kerja Perangkat Daerah (RKA-SKPD) Rencana Strategis (Renstra) SKPD}

Menurut Peraturan Pemerintah Republik Indonesia No. 58 Tahun 2005 "SKPD menyusun rencana strategis yang selanjutnya disebut RenstraSKPD yang memuat visi, misi, tujuan, strategi, kebijakan, program dan kegiatan pembangunan yang bersifat indikatif sesuai dengan tugas dan fungsinya masing-masing".

Peraturan Menteri Dalam Negeri No 54 Tahun 2010 " Renstra SKPD adalah dokumen perencanaan SKPD untuk periode 5 (lima) tahun dengan sistematika penulisan mencakup :

1. Pendahuluan

2. Gambaran pelayanan SKPD

3. Isu-isu trategis berdasarkan tugas pokok dan fungsi

4. Visi, misi, tujuan dan sasaran, strategi dan kebijakan

5. Rencana program kegiatan, indikator kinerja, kelompok sasaran dan pendanaan indikatif
6. Indikator kinerja SKPD yang mengacu kepada tujuan dan sasaran RPJMD

\section{Rencana Kerja (Renja) SKPD}

Menurut Peraturan Pemerintah Republik Indonesia No. 58 Tahun 2005 "Renja SKPD merupakan penjabaran dari Renstra SKPD yang disusun berdasarkan evaluasi pencapaian pelaksanaan program dan kegiatan tahun-tahun sebelumnya".

Renja SKPD adalah dokumen perencanaan SKPD untuk periode 1 (satu) tahun, yang memuat kebijakan, program, dan kegiatan pembangunan baik yang dilaksanakan langsung oleh pemerintah daerah maupun yang ditempuh dengan mendorong partisipasi masyarakat.

Adapun perumusan rancangan Renja SKPD adalah

a. Pengolahan data dan informasi;

b. Analisis gambaran pelayanan SKPD;

c. Mereview hasil evaluasi pelaksanaan Renja SKPD tahun lalu berdasarkan Renstra SKPD;

d. Isu-isu penting penyelenggaraan tugas dan fungsi SKPD;

e. Telaahan terhadap rancangan awal RKPD;

f. Perumusan tujuan dan sasaran;

g. Penelaahan usulan program dan kegiatan dari masyarakat;

h. Perumusan kegiatan prioritas;

i. Penyajian awal dokumen rancangan Renja SKPD;

j. Penyempurnaan rancangan Renja SKPD;

k. Pembahasan forum SKPD; dan

1. Penyesuaian dokumen rancangan Renja SKPD sesuai dengan prioritas dan sasaran pembangunan tahun rencana dengan mempertimbangkan arah dan kebijakan umum 
pembangunan daerah, arahan menteri terkait dan SPM

\section{Pedoman Penyusunan Rencana Kerja dan Anggaran SKPD \\ Menurut Nordiawan (2005:89) :}

Berdasarkan nota kesepakatan KUA dan PPAS, Tim Anggaran Pemerintah menyusun Pedoman Penyusunan Rencana Kerja dan Anggaran Satuan Kerja Perangkat Daerah (RKA-SKPD) sebagai acuan bagi SKPD dalam menyusun RKA-SKPD.

Pedoman penyusunan

RKA-SKPD mencakup:

a. PPA yang dialokasikan untuk setiap program SKPD berikut rencana pendapatan dan pembiayaan.

b. Sinkronisasi program dan kegiatan antar-SKPD dengan kinerja SKPD berkenaan sesuai dengan standar pelayanan minimal yang telah ditetapkan.

c. Batas waktu penyampaian RKA-SKPD kepada PPKD.

d. Hal-hal lainnya yang perlu mendapatkan perhatian dari SKPD terkait dengan prinsipprinsip peningkatan efisiensi, efektivitas, transparansi, dan akuntabilitas penyusunan anggaran dalam rangka pencapaian prestasi kerja.

e. Dokumen sebagai lampiran meliputi KUA, PPA, kode rekening APBD, format RKASKPD, analisis standar belanja, dan standar satuan harga.

\section{Rencana Kerja dan Anggaran SKPD (RKA-SKPD)}

Menurut PP RI Nomor 58 Tahun 2005 "RKA-SKPD disusun dengan menggunakan pendekatan kerangka pengeluaran jangka menengah daerah, penganggaran terpadu dan penganggaran berdasarkan prestasi kerja".

$$
\text { Penyusunan }
$$

RKA-SKPD

dengan pendekatan kerangka pengeluaran jangka menengah dilaksanakan dengan menyusun prakiraan maju yang berisi perkiraan kebutuhan anggaran untuk program dan kegiatan yang direncanakan dalam tahun anggaran berikutnya dari tahun anggaran yang direncanakan dan merupakan implikasi kebutuhan dana untuk pelaksanaan program dan kegiatan tersebut pada tahun berikutnya. Sedangkan penyusunan RKA-SKPD dengan pendekatan penganggaran terpadu dilakukan dengan mengintegrasikan seluruh proses perencanaan dan penganggaran di lingkungan SKPD untuk menghasilkan dokumen rencana kerja dan anggaran. Dan pendekatan penganggaran berdasarkan prestasi kerja, dilakukan dengan memperhatikan keterkaitan antara pendanaan dengan keluaran dan hasil yang diharapkan dari kegiatan dan program termasuk efisiensi dalam pencapaian keluaran dan hasil tersebut.

Demi terlaksananya penyusunan RKA-SKPD berdasarkan pendekatan kerangka pengeluaran jangka menengah daerah, penganggaran terpadu, penganggaran berdasarkan prestasi kerja, dan terciptanya kesinambungan RKA-SKPD, kepada SKPD mengevaluasi hasil pelaksanaan program dan kegiatan 2 tahun anggaran sebelumnya sampai dengan semester pertama tahun anggaran berjalan. Evaluasi tersebut bertujuan untuk menilai program dan kegiatan yang belum dapat dilaksanakan dan/atau belum diselesaikan tahun-tahun sebelumnya akan dilaksanakan dan/atau diselesaikan pada tahun yang direncanakan atau 1 tahun berikutnya dari tahun yang direncanakan. 
Dalam hal suatu program dan kegiatan merupakan tahun terakhir untuk pencapaian prestasi kerja yang ditetapkan, harus dianggarkan pada tahun yang direncanakan.

Menurut Nordiawan (2005:91) :

Penyusunan RKA-SKPD
berdasarkan prestasi kerja
didasarkan pada:

a. Indikator Kinerja

Ukuran keberhasilan yang akan

dicapai dari program dan kegiatan yang akan direncanakan.

b. Capaian atau target kinerja

Merupakan ukuran prestasi kerja yang akan dicapai yang berwujud kualitas, kuantitas, efisiensi dan efektivitas pelaksanaan dari setiap program dan kegiatan.

c. Standar Analisis Belanja

Merupakan penilaian kewajaran atas beban kerja dan biaya yang digunakan untuk melaksanakan suatu kegiatan.

d. Standar Satuan Harga

Harga Satuan setiap unit barang/jasa yang berlaku di suatu daerah yang ditetapkan dengan Keputusan Kepala Daerah.

e. Standar Pelayanan Minimal

Merupakan tolak ukur kinerja dalam menentukan pencapaian jenis dan mutu pelayanan dasar yang merupakan urusan wajib daerah.

RKA-SKPD yang telah disusun oleh SKPD disampaikan kepada pejabat pengelola keuangan daerah untuk dibahas lebih lanjut oleh Tim Anggaran Pemerintah Daerah. Pembahasan oleh Tim Anggaran Pemerintah Daerah dilakukan untuk menelaah kesesuaian antara RKASKPD dengan kebijakan umum APBD, prioritas dan plafon anggaran, prakiraan maju yang telah disetujui tahun anggaran sebelumnya, dokumen perencanaan lainnya, capaian kinerja, indikator kinerja, standar analisis belanja, standar satuan harga dan standar pelayanan minimal.

Jika pada hasil pembahasan RKA-SKPD terdapat ketidaksesuaian maka SKPD melakukan penyempurnaan. RKA-SKPD yang telah disempurnakan oleh SKPD disampaikan kepada Pejabat Pengelola Keuangan Daerah (PPKD) sebagai bahan penyusunan Raperda tentang APBD dan rancangan peraturan kepala daerah tentang pejabaran APBD. Raperda tentang APBD yang telah disusun tersebut kemudian disampaikan kepada kepala daerah. Selanjutnya Raperda tentang APBD ini disampaikan kepada DPRD untuk dibahas lebih lanjut. Akan tetapi, sebelum disampaikan kepada DRPD, Raperda tentang APBD harus disosialisasikan kepada masyarakat. Sosialisasi ini bersifat memberikan informasi mengenai hak dan kewajiban pemerintah daerah serta masyarakat dalam pelaksanaan APBD tahun anggaran yang direncanakan. Penyebarluasan rancangan peraturan daerah tentang APBD dilaksanakan oleh Sekretaris Daerah.

Setelah mendapat persetujuan DPRD, Raperda APBD diserahkan kepada Gubernur/Menteri Dalam Negeri untuk dievaluasi. Setelah diserahkan kepada Gubernur/Menteri Dalam Negeri untuk dievaluasi. Setelah melewati tahapan evaluasi, dapat dilakukan penetapan RAPBD menjadi APBD yang dituangkan dalam Peraturan Daerah (Perda). 
Gambar 1

Bagan Alir Pengerjaan RKA- SKPD

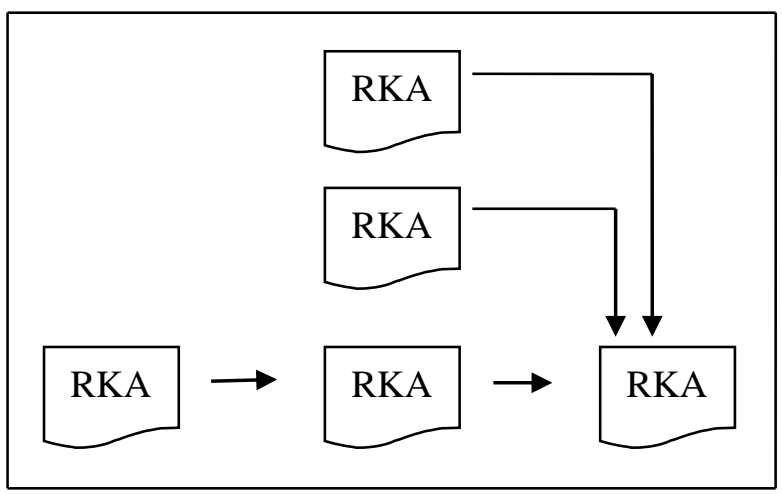

Sumber : Yodi Haya, Worshop

Reformasi Pengelolaan Keuangan

Daerah, 2008

Keterangan :

1. RKA-SKPD : Rincian Anggaran Pendapatan dan Belanja SPKD

2. RKA-SKPD 1 : Rincian Anggaran Pendapatan SKPD

3. RKA-SKPD 2.1 : Rincian Anggaran Belanja Tidak Langsung SKPD

4. RKA-SKPD 2.2 : Rekapitulasi Rincian Anggaran Belanja Langsung menurut Program dan Kegiatan SKPD

5. RKA-SKPD 2.2.1 : Rincian Anggaran Belanja langsung Menurut Program dan Perkegiatan SKPD

\section{Tinjuan Penelitian Terdahulu}

Penelitian sejenis telah dilakukan sebelumnya oleh Dewi (2012) dengan judul "Analisis Proses Penyusunan Anggaran Satuan Kerja Perangkat Daerah (RKA-SKPD) Dinas Pekerjaan Umum Kabupaten Deli Serdang”. Hasil dari penelitian menyatakan bahwa
Rencana kerja Dinas Pekerjaan Umum Kabupaten Deli Serdang tahun 2011 adalah penjabaran Rencana Strategis Dinas Pekejaan Umum tahun 20092014 dengan mengacu pada Rencana Pembangunan Jangka Menengah Kabupaten Deli Serdang Tahun 20092014 yang merupakan bahan acuan dan pedoman bagi pelaksanaan kegiatan Dinas Pekerjaan Umum. Dengan menggunakan analisis SWOT yaitu kekuatan (tersedianya UndangUndang/Peraturan-Peraturan, tersedianya peralatan/alat berat yang memadai), kelemahan (kompetensi SDM ada yang masih rendah, pendataan belum akurat dam terbatasnya dana APBD), peluang (partisipasi masyarakat dan dunia usaha, sosial kontrol, pendidikan dan pelatihan, penegakan hukum), ancaman (tonase angkutan barang, profesionalisme jasa konsultasi, bencana alam, tata guna lahan), maka tersusunlah Rencana Kerja dan Anggaran (RKA) Dinas Pekerjaan Umum Kabupaten Deli Serdang yang sesuai dengan visi dan misi Dinas PekerjaanUmum Kabupaten Deli Serdang.

Bangun Parlaungan Ritonga (2008) melakukan penelitian dengan judul "Proses Penyusunan Anggaran Satuan Kerja Perangkat Daerah (RKASKPD) Badan Perencanaan Pembangunan Daerah Pemerintah Kabupaten Tapanuli Selatan", hasil dari penelitian ini menunjukan bahwa dalam proses penyusunan anggaran satuan kerja perangkat daerah (RKA-SKPD) Badan Perencanaan Pembangunan Daerah Pemerintah Kabupaten Tapanuli Selatan dengan mengacu pada Rencana Strategis Bappeda Kabupaten Tapanuli Selatan Tahun 2006-2010 yang merupakan bahan acuan dan pedoman bagi pelaksanaan kegiatan BAPPEDA. Dengan menggunakan 
analisis kekuatan, kelemahan, peluang dan tantangan dalam menganalisis penyusunan strategis dalam penyusunan rencana anggaran BAPPEDA. Maka tersusunlah Rencana Kerja Anggaran (RKA) BAPPEDA Kabupaten Tapanuli Selatan yang sesuai dengan visi misi BAPPEDA Kabupaten Tapanuli Selatan.

\section{Kerangka Konseptual}

Kerangka konseptual penelitian dapat digambarkan sebagai berikut :

Gambar 3

Kerangka Konseptual

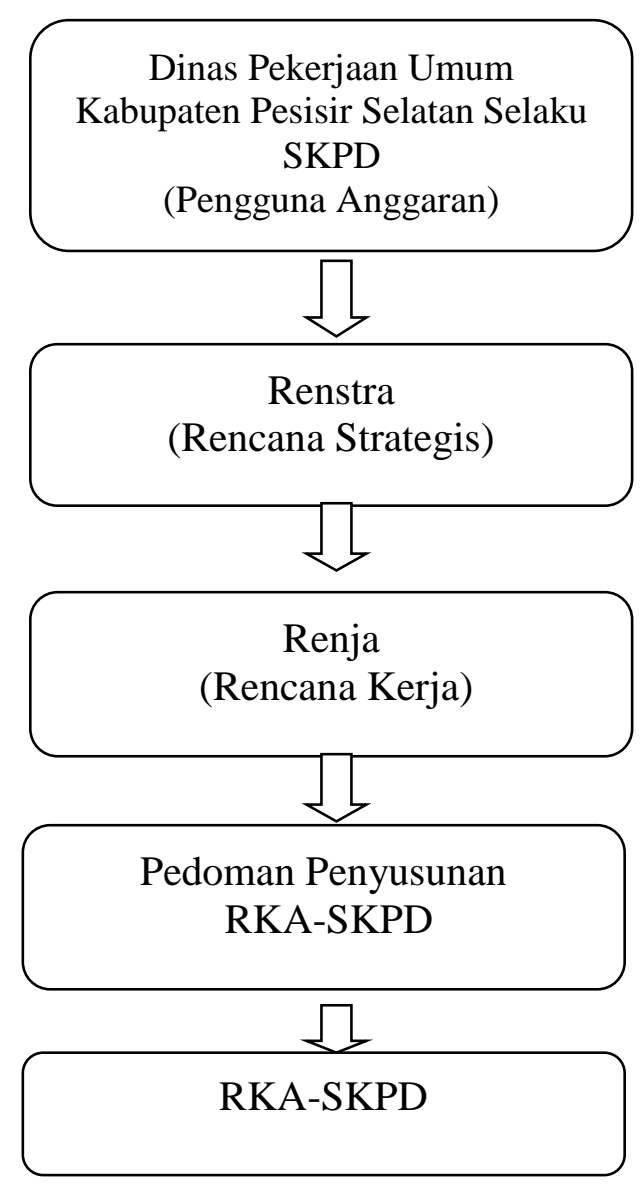

\section{METODE PENELITIAN}

\subsection{Lokasi Penelitian}

Adapun tempat penelitian dilakukan di Pemerintahan Kabupaten Pesisir Selatan tepatnya di Dinas
Pekerjaan Umum yang beralamat di Jalan Jendral Sudirman Painan - Sago.

\subsection{Jenis Data dan Sumber Data}

Data yang dikumpulkan dan digunakan untuk mendukung penulisan adalah :

1. Data Primer yaitu data yang diperoleh langsung dari objek penelitian yaitu Pemerintahan

Kabupaten Pesisir Selatan terutama di Dinas Pekerjaan Umum baik dalam teknik wawancara maupun dokumentasi terhadap bagianbagian yang memiliki keterkaitan dengan permasalahan.

2. Data Sekunder yaitu data yang diperoleh dalam bentuk yang sudah jadi, baik berupa data dari penelusuran catatan dan dokumen-dokumen resmi serta sumber-sumber lainnya berupa data runtut waktu (time series) Dinas Pekerjaan Umum Kabupaten Pesisir Selatan maupun merupakan publikasi yang relevan dengan masalah yang dibahas, antara lain data mengenai sejarah singkat, struktur organisasi maupun job description.

\subsection{Teknik Pengumpulan Data}

Metode yang dilakukan penulis dalam rangka merampung pembahasan mengenai penyusunan dan penetapan anggaran adalah :

1) Penelitian Kepustakaan (Library Research), yakni :

Penelaahan berdasarkan kepustakaan dimana data dan informasi yang dibutuhkan diperoleh dengan membaca buku-buku, majalah-majalah ilmiah, dan tulisan lain yang berkaitan dengan judul tulisan ini. Penelitian ini dilakukan sebelum dan sesudah penelitian ke perpustakaan.

2) Penelitian Lapangan (Field Research), yakni : 
Penelitian yang langsung dilakukan pada objek yang dipilih atau diteliti. Data dan informasi yang dibutuhkan diperoleh dengan cara mengadakan wawancara terhadap pihak-pihak yang dapat memberikan informasi yang diperlukan dalam objek penelitian. Dalam hal ini penulis langsung mengadakan penelitian pada Dinas Pekerjaan Umum Kabupaten Pesisir Selatan melalui dua cara, yakni:

a. Wawancara, yakni mengadakan tanya jawab dengan bagian Sekretariat, bagian perencanaan dan pelaporan dan bagianbagian lain yang berhubungan dengan objek penelitian.

b. Observasi, yakni mengadakan pengamatan langsung di Dinas Pekerjaan Umum Kabupaten Pesisir Selatan mengenai perencanaan dan pelaksanaan anggaran pendapatan dan belanja daerah, terutama yang berkaitan dengan dokumendokumen dan aktifitas-aktifitas dalam pengelolaan anggaran yang dimaksud.

\subsection{Metode Analisis Data}

Metode analisis data yang digunakan adalah metode kualitatif deskriptif, yaitu mengumpulkan, menyusun, mengklasifikasikan, dan menganalisa data untuk memberikan gambaran dan jawaban yang jelas dan akurat dari perumusan masalah dan kemudian melakukan evaluasi terhadap data yang dikumpulkan tersebut dan menganalisis hubungannya dengan masalah yang dibahas untuk kemudian membuat kesimpulan dan saran-saran yang dianggap penting.

\section{HASIL DAN PEMBAHASAN \\ Proses Penyusunan RKA-SKPD yang Dikoordinasikan oleh Tim Penyusunan Anggaran Daerah (TPAD)}

Dinas Pekerjaan Umum melakukan penyusunan RKA-SKPD yang dikoordinasikan oleh Tim Anggaran Pemerintah Daerah (TAPD) dalam hal ini pihak Bappeda serta Sekretariat Daerah. TPAD menyiapkan surat edaran kepala daerah tentang penyusunan RKA-SKPD yang harus diterbitkan paling lambat awal bulan agustus tahun berjalan. Setiap unit kerja di lingkungan Pemerintah Kabupaten Pesisir Selatan diminta untuk menyusun Rencana Kerja Anggaran (RKA-SKPD) dengan mengisi formulir-formulir kelengkapan sebagai berikut :

1. RKA-SKPD: Ringkasan RKA SKPD

2. RKA-SKPD 1 : Rincian RKA Pendapatan SKPD

3. RKA-SKPD 2.1 : Rincian RKA Belanja Tidak Langsung

4. RKA-SKPD 2.2 : Rekapitulasi RKA Belanja Langsung Menurut Program dan Kegiatan SKPD

5. RKA-SKPD 2.2.1 : Rincian RKA Belanja Langsung Program dan Per Kegiatan SKPD

\section{Analisis terhadap Program dan Sasaran Rencana Kerja}

Dinas Pekerjaan Umum

Kabupaten Pesisir Selatan menyusun program dan kegiatan Berdasarkan Rencana Kerja Dinas Pekerjaan Umum Tahun 2013 serta uraian rumusan Rencana Strategis Dinas Pekerjaan Umum Tahun 2011-2015.

Adapun program yang disusun melalui proses penyusunan strategi dan prioritas dari arah kebijakan, visi dan misi, tujuan, sasaran, tugas, fungsi, adalah sebagai berikut:

\section{Program di Bidang Sekretariat}


a. Program Pelayanan Administrasi Perkantoran

Tujuan program untuk mendukung pelaksanaan penyelenggaraan kepemerintahan daerah kabupaten Pesisir Selatan agar efisien dan efektif. Sasaran program adalah tersedianya belanja jasa komunikasi, listrik, air, jasa kebersihan kantor, belanja peralatan/perlengkapan untuk mendukung kegiatan administrasi perkantoran.

1. Penyediaan Jasa Komunikasi, sumber daya air dan listrik Rp. 73.920.000,-

Sasaran yang telah terealisasi : terlaksananya belanja telepon, air, listrik dan belanja kawat/faksimili/internet.

2. Penyediaan Jasa Kebersihan Kantor Rp. 83.500.000,Sasaran yang telah terealisasi :

a. Tersedianya peralatan kebersihan dan bahan pembersih.

b. Tersedianya jasa keamanan dan kebersihan kantor.

3. Penyediaan Alat Tulis Kantor Rp. 34.999.100,-

Sasaran yang telah terealisasi : tersedianya alat tulis kantor habis pakai.

4. Penyediaan Peralatan dan Perlengkapan Kantor Rp. 70.890.000,-

Sasaran yang telah terealisasi : tersedianya peralatan dan perlengkapan kantor berupa 4 unit $\mathrm{AC}, 3$ unit komputer PC, 3 unit Printer, 1 unit scaner, 1 unit kursi eselon II, dan 1 unit proyektor.

c. Program Peningkatan Disiplin Aparatur

Tujuan program untuk mendukung tugas dan administrasi pemerintahan yang efektif dan efisien. Sasaran program adalah tersedianya sarana dan prasarana pendukung tugas sehingga terciptanya disiplin aparatur di unit Dinas Pekerjaan Umum.

1. Pengadaan Pakaian Kerja Lapangan Pegawai Kebersihan Rp. 29.599.720,-

Sasaran yang telah terealisasi : tersedianya pengadaan pakaian kerja lapangan untuk pegawai kebersihan.

d. Program Peningkatan Kapasitas Sumber Daya Aparatur

Tujuan program adalah untuk meningkatkan kapasitas sumber daya manusia yang lebih baik. Sasaran program tersedianya sumber daya manusia yang berkualitas untuk mendukung kegiatan organisasi.

1. Bimbingan Teknis Implementasi Peraturan Perundang - undangan $\mathrm{Rp}$. 10.000.000,-

Sasaran yang telah terealisasi : terlaksananya bimbingan teknis dan implementasi peraturan perundang-undangan bagi pegawai.

2. Pendidikan dan Pelatihan Formal Rp. 15.000.000,-

Sasaran yang telah terealisasi : terlaksananya kursus singkat/pelatihan kursus-kursus singkat/pelatihan bagi pegawai.

e. Program Monitoring, Evaluasi, dan Pelaporan

Tujuan program adalah untuk mendukung tugas dan administrasi pemerintahan yang efektif dan efisien. Sasaran program adalah tersedianya monitoring dan evaluasi kegiatan di lingkungan dinas pekerjaan umum, sinkronisasi RPIJM - Cipta Karya, pembuatan data base Cipta Karya, terlaksananya singkronisasi program DAK dan APBN.

1. Monitoring Evaluasi dan Pelaporan Rp. 500.828.300,- 
Sasaran yang telah terealisasi : terlaksananya monitoring evaluasi dan pelaporan kegiatan di lingkungan Dinas Pekerjaan Umum.

2. Sinkronisasi RPIJM- Cipta Karya Rp. 75.811.400,-

Sasaran yang telah terealisasi : terlaksananya pengentrian datadata Sinkroni RPJM Cipta Karya.

3. Pembuatan Data Base Cipta Karya Rp. 50.000.000,-

Sasaran yang telah terealisasi : terlaksananya pembuatan data base Cipta Karya.

4. Singkronisasi Program DAK dan APBN Rp. 82.000.000,Sasaran yang telah terealisasi : terlaksananya singkronisasi program DAK dan APBN.

\section{Program di Bidang Bina Teknik}

a. Program Rehabilitasi/Pemeliharaan Jalan dan Jembatan

Tujuan program adalah untuk mendukung tugas dan administrasi pemerintahan yang efektif dan efisien. Sasaran program adalah tersedianya perencanaan terhadap rehabilitasi/pemeliharaan jalan dan jembatan.

1. Perencanaan

Rehabilitasi/Pemeliharaan Jalan

Kabupaten (DAK 2014)

Rp.150.000.000,-

Sasaran yang telah terealisasi : tersedianya perencanaan rehabilitasi/pemeliharaan jalan kabupaten (DAK 2014).

2. Perencanaan

Rehabilitasi/Pemeliharaan Jalan Kabupaten (DAK Paket IV) Rp. 50.000.000,-

Sasaran yang telah terealisasi : tersedianya perencanaan rehabilitasi/pemeliharaan jalan kabupaten (DAK Paket IV). b. Program Pengembangan dan Pengelolaan Jaringan Irigasi, Rawa, dan Jaringan Pengairan Lainnya

Tujuan program adalah untuk mendukung tugas dan administrasi pemerintahan yang efektif dan efisien. Sasaran program adalah tersedianya perencanaan terhadap kegiatan sarana dan prasarana air bersih perkotaan pedesaan.

1. Perencanaan Pembangunan Sarana Air Bersih 2014 Rp. 50.000.000,-

Sasaran yang telah terealisasi : tersedianya perencanaan pembangunan sarana air bersih 2014.

c. Program Peningkatan Sarana dan Prasarana Kebinamargaan

Tujuan program adalah untuk mendukung tugas dan administrasi pemerintahan yang efektif dan efisien. Sasaran program adalah terpeliharaanya peralatan dan perlengkapan bengkel, alat berat dan alat-alat ukur dan bahan laboratorium yang mendukung kegiatan kebinamargaan.

1. Rehabilitasi/pemeliharaan peralatan dan perlengkapan bengkel dan alat berat $\mathrm{Rp}$. 200.625.000,-

Sasaran yang telah terealisasi :
a. Dilakukan service terhadap alat-alat berat
b. Dilakukannya pelatihan laboratorium
c. Pengadaan note book 2 unit, printer 2 unit, camera 1 unit

2. Rehabilitasi/pemeliharaan alatalat ukur dan bahan laboratorium kebinamargaan Rp. 26.000.000,-

Sasaran yang telah terealisasi : terpeliharaanya alat-alat ukur laboratorium 
d. Program Monitoring, Evaluasi, dan Pelaporan

Tujuan program untuk mendukung pelaksanaan penyelenggaraan kepemerintahan daerah kabupaten Pesisir Selatan agar efisien dan efektif. Sasaran program adalah tersedianya pemutakhiran data base jalan dan jembatan paket I, II, III, IV, dan V.

1. Pemutakhiran Data Base Jalan dan Jembatan Rp. 300.000.000,-

Sasaran yang telah terealisasi : tersedianya pemutakhiran Data Base Jalan dan Jembatan paket I,II,III, IV, dan V.

\section{Program di Bidang Bina Marga}

a. Program Pembangunan Jalan dan Jembatan

Tujuan program adalah untuk mendukung tugas dan administrasi pemerintahan yang efektif dan efisien. Sasaran program adalah terbangunnya jaringan jalan kabupaten dan jalan strategis untuk membuka daerah terisolir.

1. Pembangunan Jalan Salido carocok Rp. 9.831.300.000,-

Sasaran yang telah terealisasi : tersedianya akses jalan wisata salido - carocok di Salido.

2. Pembangunan Jalan Tampunik - Koto Kandis Rp. 200.000.000,-

Sasaran yang telah terealisasi : tersedianya jalan Tampuniak Koto Kandis.

3. Pembangunan Jalan Kabupaten I Rp. 700.000.000,-

Sasaran yang telah terealisasi :
a. Tersedianya jalan Pasar Tapan.
b. Penyiapan lahan Pesantren Kambang

b. Program Rehabilitasi/Pemeliharaan Jalan dan Jembatan
Tujuan program adalah untuk mendukung tugas dan administrasi pemerintahan yang efektif dan efisien. Sasaran program adalah terpeliharaanya jaringan jalan kabupaten dan Jembatan Pedesaan.

1. Rehabilitasi/Pemeliharaan Jalan Kabupaten (DAK 2013) Rp. 22.686.486.600,-

Sasaran yang telah terealisasi :

a. Terlaksananya rehabilitasi/pemelihar aan Jalan kabupaten paket I : Jl. Gurun Panjang - Sei. Talang, Jl. Koto Ranah - Bayang Janiah, Jl. Bukit Kaciak - Koto Ranggo, Jl. BaruangBaruang balantai Kelok Rumbai, Jl. Koto Baru - Koto Rawang, Jl. Koto Rawang - Lakitan, Jl. Taratak baru Sekitarnya.

b. Terlaksananya rehabilitasi/pemelihar aan Jalan kabupaten paket II : Jl. Kalumpang - Limau Manis, Jl. Labuhan Tebing Tinggi, Jl. Lagan Hilir - Bukit Putus dalam, Jl. Padang Tandikek Balambahan, Jl. Ps. Bukit - Alang Sungkai.

c. Terlaksananya rehabilitasi/pemelihar aan Jalan kabupaten paket III : Jl. Simpang Silaut III - TSM Silaut II, Jl. Talang Kubu Penggantingan, Jl. 
Simp. Tj. Beringin $\mathrm{Tj}$. Beringin, Jl. Ampang Tanah sekitarnya.

d. Terlaksananya rehabilitasi/pemelihar aan Jalan kabupaten paket IV : Jl. Tanjung Durian - sekitarnya, J1. Bukit Putus Carocok Koto, Jl. Koto Baru sekitarnya, J1. Koto Keduduk - Koto Panjang, Jl. Simp. Perkebunan Lansano.

2. Rehabilitasi Jembatan Pedesaan Rp. 1.085.000.000,Sasaran yang telah terealisasi :

a. Terehabilitasinya jembatan pedesaan yakni : Rehabilitasi Jembatan Pasar Baruang-Baruang Balantai, Rehabilitasi Jembatan gantung Belakang SMP Bungo Pasang, Rehabilitasi Jembatan Gantung Tambang, Rehabilitasi Jembatan Ujung Air Padat karya, Rehab Jembatan Aua Begalung, Rehablitasi Jembatan KLK Salido, Rehabilitasi Jembatan Bely Silaut I, Rehabilitasi Jembatan Gantung Nyiur Gading, Rehabilitasi Jembatan Gantung Pasir Ganting.

c. Program Pembangunan Infrastruktur Perdesaan/Nagari

Tujuan program adalah untuk mendukung tugas dan administrasi pemerintahan yang efektif dan efisien. Sasaran program adalah meningkatkan kualitas dan kuantitas jalan desa sehingga terlaksananya pembangunan jalan dan jembatan pedesaan.

1. Pembangunan Sarana dan Prasarana Daerah Tertinggal DAK 2013 Rp. 1.100.000.000,Sasaran yang telah terealisasi :

a. Terlaksananya pembangunan sarana dan prasarana daerah tertinggal (DAK) yaitu : Rehabilitasi Jembatan Gantung Ujung Pasir Koto Panjang, Baruang-Baruang Balantai.

2. Pembangunan Jalan dan Jembatan Desa I Rp. 4.001.506.700,Sasaran yang telah terealisasi :

a. Terlaksananya pembangunan jalan dan jembatan desa paket $\mathrm{A}$ : Jln Gadih Basanai Api - Api, Pemb. Jl. Evakuasi Tsunami Api - Api, Gang Bunda Kp. Teluk Belibis Kenag. Api - Api, Pemb. Jln. Ujung Tanah Kp. Tanjung Durian.

b. Terlaksananya pembangunan jalan dan jembatan desa paket B : Pemb. Jln. Ranah Panjang - Ladang Kp. Limau asam, Pemb. Jl. Pos Ronda Kabun Limau Asam, Peningkatan Jl. Ujung Tanah Limau Asam, Peningkatan Jln. Gurun Laweh Limau Asam.

c. Terlaksananya pembangunan jalan dan jembatan desa paket $\mathrm{C}$ 
: Peningkatan Jl. Pdg Bungo Kapeh Panji Jaya, Kp. Dalam Koto Baru, Kp. Dalam Limau Asam Tj. Durian, Jln. Ulu Air Kp. Sei Putih Kenagarian Gurun Panjang, Cor Beton Jln Kapujan, Pemb. Jln. Pd. Bungo Kp. Apa Jaya Nag. Kapeh Panji Talaok.

d. Terlaksananya pembangunan jalan dan jembatan desa paket D : Rabat Beton Jalan Kp. Duku Utara, Rabat Beton Jalan Kampung Baru, Rabat Beton Jalan Koto Kaciak Koto Kp. Tanjung, Rabat Beton Jalan Balik Bukik, Rabat Beton Jalan Tanah Lapang, Rabat Beton Jalan Ranah.

e. Terlaksananya pembangunan jalan desa dan jembatan paket E : Jln. Lingkar Belakang Mesjid, Jln. Sei. Tanuk - Pisang Aneh, Jln. Sei Sangir Kp. Tanjung Dan Jln Ke Kantor Wali, Jln. Lubuk Ganggo dengan Kampung Melayu.

f. Terlaksananya pembangunan jalan dan jembatan desa paket $\mathrm{F}$ : Pemb. Jln. Sawah Payek, Kubang Bayang, Jln. Gardu Muaro Api-Api, Jln. Calau, Bayang Utara, Jln. Cor Beton Limau -
Limau Pancung Tebal, Jln. Taratak Teleang.

g. Terlaksananya pembangunan jalan dan jembatan desa paket $G$ : Perbaikan Jembatan Kp. Nagari Taratak Sungai lundang, Pemb. Jln. Kampung Tanjung Nagari Duku Utara, Pemb. Jln. Lingkar Kp. Sawah, Pemb. Rabat Beton Jalan Jaruai, Pemb. Jln. Gubuk Taratak Sei Lundang, Peningkatan Jl. Lahan Perkebunan Duku.

h. Terlaksananya pembangunan jalan dan jembatan desa paket I : Pemb. Jl Kapuh Parak, Pemb. J1. Ke Pos Ronda Kp. Kapuh.

i. Terlaksananya pembangunan jalan dan jembatan desa paket II : Pemb. Jl. Lubuak Baeh Desa Baru Sungai Lundang, Cor Rabat Beton J1. Kenanga sawah Liat tarusan.

j. Terlaksananya pembangunan jalan dan jembatan desa paket III : Pemb. Jln. ke Muaro Mandeh, Pemb. Jl. Koto Pulai Sungai Sangkir.

k. Terlaksananya pembangunan jalan dan jembatan desa paket IV : Rabat Beton Jl. Seberang Jembatan Gantung, Rabat Beton Jl. Gurun Jua Lereng, Pemb. jl. Tingkuring - 
Durian Kodok Sei

Tanuk.

1. Terlaksananya pembangunan jalan dan jembatan desa paket $\mathrm{V}$ : Pemb. Jln. Lingkar Simp. Balai Akek Kapuh.

m. Terlaksananya pembangunan jalan dan jembatan desa paket VI : Pemb. Jl. Nagari Duku Utara.

n. Terlaksananya pembangunan jalan dan jembatan desa paket VII : Pemb. Jl. Kabun Simp. Ampang Pulai dan Jl. Kumbawa Teluk Raya, Tarusan, Pemb. Jl. Gunung Cerek Kp. Gn. Cerek, Gurun Panjang.

o. Terlaksananya pembangunan jalan dan jembatan desa paket VIII : Peningkatan Jl. Tabiang Indah dan Kabun Tanjung Durian.

p. Terlaksananya pembangunan jalan dan jembatan desa paket IX : Pembuatan Jl. sekitar Mesjid Darussalam Pasar Baru, Bayang.

q. Terlaksananya pembangunan jalan dan jembatan desa paket $\mathrm{X}$ : Peningkatan Jl. Baru Desa Parik Salak Nagari Mandeh, Pemb. J1. Buah AmbacangSei Talang Kapuh Utara.

r. Terlaksananya pembangunan jalan dan jembatan desa paket
XI: Lanjutan

Pembangunan

Jembatan Cumateh

Nagari Duku Tarusan.

s. Terlaksananya

pembangunan jalan dan jembatan desa paket XII : Pemb. Jembatan Kubang Bayang.

3. Pembangunan Jalan dan Jembatan Desa II Rp. 2.410.000.000,-

Sasaran yang telah terealisasi :

a. Terlaksananya pembangunan jalan dan jembatan desa paket A : Pemb. Jln. Kp. Tengah Bayang - Koto Ranggo Lumpo, Pemb. Jln. GG. Saiyo Painan, Jln. Imam Bonjol - Jl.Setia Budi, Pemb. Jln. Evakuasi Tsunami Bukit Barangan Lumpo.

b. Terlaksananya pembangunan jalan dan jembatan desa paket B : Betonasi Jalan / Ex Kantor Desa Bungo Pasang II, Jln. Ariek Karang, Rehabilitasi Jembatan Kampung Olo Nagari Tambang, Betonasi Jln Dekat Rumah Cap Tambang / Cupak Ampo.

c. Terlaksananya pembangunan jalan dan jembatan desa paket $\mathrm{C}$ : Perbaikan Jembatan Inunang, Rabat Beton Jln. Kp. Tanjung Limau Sundai, Rabat Beton J1. Koto Panjang Kenagarian Taluak, Pemb. Jln. Beton Dari Rmh Panjang Kp. 
Bungo Pasang II Ke SMPN 3 Painan.

d. Terlaksananya pembangunan jalan dan jembatan desa paket I : Pemb. Jln. Beton di Kp. Bungo Tanjung.

e. Terlaksananya pembangunan jalan dan jembatan desa paket II : Pemb. Rabat Beton Jl. Kp. Taratak Tampatih.

f. Terlaksananya pembangunan jalan dan jembatan desa paket III : Pemb. Rabat Beton Jl. Kp. bakung Lubuk Nyiur, Pemb. rabat beton J1. tanjung Sungai Nyalo.

g. Terlaksananya pembangunan jalan dan jembatan desa paket IV : Peningkatan Jalan Lingkar Kp. Teluk Betung.

h. Terlaksananya pembangunan jalan dan jembatan desa paket $\mathrm{V}$ : Pemb. Jln. Ranah Petambuan Batu Kodi Kp. Teluk Betung.

i. Terlaksananya pembangunan jalan dan jembatan desa paket VI : Pemb. Jl. Kampung Gunung Bungkuk Lumpo, Pemb. Jl. Langung Sinayan Lumpo, Pemb. J1. Sei Gayo.

j. Terlaksananya pembangunan jalan dan jembatan desa paket VII : Pengerasan Jln Lingkar Pasar Mambo Lubuk nyiur, Peningkatan Jl. Nagari Koto Nan Tigo. k. Terlaksananya pembangunan jalan dan jembatan desa paket VIII : Pembukaan Jalan Baru Kandang Kabau / Balai Gadang.

1. Terlaksananya pembangunan jalan dan jembatan desa paket IX : Pemb. Jln Belakang SD Bungo Pasang Sungai Salak.

4. Pembangunan Jalan dan Jembatan Desa III Rp. 3.240.000.000,-

Sasaran yang telah terealisasi :

a. Terlaksananya pembangunan jalan dan jembatan Paket A : Pemb. Jln. Pincuran Koto Merapak, Pemb. Jln Siano Bukit Layang, Pemb. Jln Timbulun Nyiur Gading.

b. Terlaksananya pembangunan jalan dan jembatan Paket B : Pemb. Jln. Kayu Gadang Surantih, Pemb. Betonasi Jln Langgai Lubuk Talang, Pemb. Rabat Beton Kampung Gantiang Ampalu, Pemb. Rabat Beton Jln. Kampung Ampalu.

c. Terlaksananya pembangunan jalan dan jembatan Paket $\mathrm{C}$ : Harapan Nelayan Sutera.

d. Terlaksananya pembangunan jalan dan jembatan Paket D : Jln. Simpang Cumangko, Jln. Lingkar Desa Padang Tabek - Lubuk Begalung.

e. Terlaksananya pembangunan jalan dan 
jembatan Paket I : Pemb.

Jln. Kayu Aro Laban.

f. Terlaksananya pembangunan jalan dan jembatan Paket II : Pemb. Jln. Kayu Gadang Koto Tinggi.

g. Terlaksananya pembangunan jalan dan jembatan Paket III : Pengerasan Jln. Kp. Simpuding Rawang Gunung Lelo.

h. Terlaksananya pembangunan jalan dan jembatan Paket IV : Pemb. Jln. Cor Pemakaman Umum Lansano Nagari Lansano.

i. Terlaksananya pembangunan jalan dan jembatan Paket $\mathrm{V}$ : Betonasi dan Penyambungan Jalan OMS.

j. Terlaksananya pembangunan jalan dan jembatan Paket VI : Pemb. Rabat Beton Kp. Alai Ampiang Parak, Pemb. rabat beton $\mathrm{Kp}$. Gunung Malelo.

k. Terlaksananya pembangunan jalan dan jembatan Paket VII : Peningkatan jalan Padang Tae dalam Bukit Pantai.

1. Terlaksananya pembangunan jalan dan jembatan Paket VIII : Pemb. Jln. Lingkar Nagari Aur Duri Surantih, Pemb. Jl. Usaha Tani Simpuding Rawang Gunung Malelo
Lingkar Nagari Aur Surantih.

m. Terlaksananya pembangunan jalan dan jembatan Paket IX : Pemb. Jln. Kp. Caniago Gg. Malelo.

n. Terlaksananya pembangunan jalan dan jembatan Paket $X$ : Pemb. Jln. Ujung Padang - Durian.

o. Terlaksananya pembangunan jalan dan jembatan Paket XI : Drainase Jln. Kp. Kayu Gadang.

p. Terlaksananya pembangunan jalan dan jembatan Paket XII : Peningkatan $\mathrm{Jl}$. Seberang Tarok.

q. Terlaksananya pembangunan jalan dan jembatan Paket XIII : Pemb. Jln. Kepalo Banda - Kubu Randah Kambang Timur.

5. Pembangunan Jalan dan Jembatan Desa IV Rp. 2.225.054.000,-

Sasaran yang telah terealisasi :

a. Terlaksananya pembangunan jalan dan jembatan Paket A : Peningkatan Jln. Rambahan I Sumedang, Peningkatan Jln. Rambahan II Sumedang, Peningkatan Jln. Pandarahan Labuhan, Pemb. Jln. Pemakaman Koto Kabun Sungai Tunu, Pemb. Jln. Pemakaman Koto Kui Balai Selasa.

b. Terlaksananya pembangunan jalan dan 
jembatan Paket B : Peningkatan Mutu Jln. Tj. Medan - Rengas (Lanjutan), Pengecoran Jl. Simp. Mesjid Padang Kayu Dadih, Pengerasan Jln. Lagan Gadang Mudik, Pemb. Parit Miring Kp. Sikumbang Pd Kayu Dadih, Pengecoran Jln. Tj. Mudik Air Haji, Pengecoran Jln. Alang Sungkai Air Haji.

c. Terlaksananya pembangunan jalan dan jembatan Paket $\mathrm{C}$ : Peningkatan Jl. Air Singkarak - Singgalang, Peningkatan Jl. Mesjid Muaro Gadang dan Jl. Mushala Simp. Muaro Pandaan, Rabat Beton J1. Mesjid " Nuriul Amal " Tandikat Air Jambu Punggasan,

Pembangunan Cor beton Jln Bandar Baru Padang Laban, Pemb. Cor Beton Jln. Koto Lanang Sungai Liku Tengah.

d. Terlaksananya pembangunan jalan dan jembatan Paket I : Rehabilitas Jl. Bukit Puyuh Air Haji.

e. Terlaksananya

pembangunan jalan dan jembatan Paket II : Cor Beton Jl. Air Jambak Sungai Liku Ateh, Pemb. Cor Beton Bukit Nibung Sungai Liku Tengah.

f. Terlaksananya pembangunan jalan dan jembatan Paket III :
Pengecoran J1. Tengah Padang.

g. Terlaksananya pembangunan jalan dan jembatan Paket IV : Pemb. Jl. Mushalla Dusun baru Sumedang, Pemb. jl. Limau Sundai - Koto Kabun Pelangai Gadang.

h. Terlaksananya pembangunan jalan dan jembatan Paket $\mathrm{V}$ : Pemb. Jl. Balah lambahan, Pemb. Jl. Sumur Ayak Nagari Pelangai Kt. Kaciak, Pemb. Jl. Baru Lumpatan - Pakia Bantaran.

i. Terlaksananya pembangunan jalan dan jembatan Paket VI : Peningkatan Jl. Bukit Puyuh di Air Sikambing.

j. Terlaksananya pembangunan jalan dan jembatan Paket VII : Pemb. Jl. Salak Baduri ke Slok Mudik.

k. Terlaksananya pembangunan jalan dan jembatan Paket VIII : Peningkatan Jl. Ujung Melang, Nagari Koto VIII Pelangai Koto, Peningkatan Jalan dan Saluran Drainase menuju Linggo Sari Baganti.

1. Terlaksananya pembangunan jalan dan jembatan Paket IX : Pemb. Jl. Dusun Baru STAI Balai Selasa.

6. Pembangunan Jalan dan Jembatan Desa V Rp. 2.675.000.000,- 
Sasaran yang telah terealisasi :

a. Terlaksananya pembangunan jalan dan jembatan Paket A : Pemb. Jln. Nagari Tanjung Pondok, Peningkatan Jln. Nagari Pasir Binjai dan Nagari Talang Binjai Silaut II, Peningkatan Jln. Nagari Binjai, Pemb. Jln. Nagari Koto Tinggi.

b. Terlaksananya pembangunan jalan dan jembatan Paket B : Peningkatan Jln. Silaut II, Pemb. Jembatan Sei Sarik, Pemb. Jln. Mushalla Darus Salam, Jln. Kp. Rantau Kentakadan Jln. Mesjid Taqwa Kp. Sindang, Pengerasan Jln. Kp. Sindang 6 Blok A.

c. Terlaksananya pembangunan jalan dan jembatan Paket $\mathrm{C}$ : Pengecoran Jln. Kantor Wali Nagari, Lunang II dan Jembatan Raih Sebelas , Pemb. Jemb. Lunang III, Pengerasan Jln. Lunang II , Pengecoran Jln. Nagari Lunang.

d. Terlaksananya pembangunan jalan dan jembatan Paket D : Pembuatan Jln. Baru Kampung Medan Jaya, Pengerasan Jln. Pertanian Kampung Rantau Kentaka, Pengerasan Jln. Ke Bukit Abang - Abang, Pemb. Sindang Tran Blk A. e. Terlaksananya pembangunan jalan dan jembatan Paket I : Pemb. Jln. Menuju Makam Inderapura, Nag Indera Pura Utara, Pemb. Jl. Menuju SD Gunung Inderapura Nagari Indera Pura Utara.

f. Terlaksananya pembangunan jalan dan jembatan Paket II : Pembuatan Jl. di Silaut.

g. Terlaksananya pembangunan jalan dan jembatan Paket III : Pengecoran J1. Nagari Lunang Selatan.

h. Terlaksananya pembangunan jalan dan jembatan Paket IV : Pemb. Pagar Ktr. Camat Tapan, Pemb. Jl. Nagari Enau.

i. Terlaksananya pembangunan jalan dan jembatan Paket $\mathrm{V}$ : Pemb. Jln. Nagari Pondok Prian Kumbung III.

j. Terlaksananya pembangunan jalan dan jembatan Paket VI : Peningkatan Jl. Wungu Rejo Nagari Lunang II.

k. Terlaksananya pembangunan jalan dan jembatan Paket VII : Pemb. Pagar Pemakaman Umum Nagari Talang koto pulai.

1. Terlaksananya pembangunan jembatan Pemb. Jembatan Nagari Kubu, Pemb. Rehab Jembatan Nagari Pondok Prian. 


\section{Program di Bidang Cipta Karya}

a. Program Peningkatan Sarana dan Prasarana Aparatur

Tujuan program yaitu untuk mendukung pelaksanaan tugas dan administrasi pemerintahan secara lebih efektif dan efesien serta terpadu. Sasaran program adalah terpeliharanya bangunan pemerintahan serta sarana dan prasarana ibadah yang representatif dan layak guna yaitu direhabnya 3 unit bangunan perkantoran, terpeliharanya bangunan rumah dinas pemerintah sebanyak 2 unit, Lanjutan Pembangunan Rumah Ibadah sebanyak 1 unit, terwujudnya pemanfaatan ruang yang nyaman dan harmonis sejalan dengan pembangunan perumahan dan permukiman.

1. Pemeliharaan Rutin / Berkala Gedung Kantor Rp. 60.000.000,-

Sasaran yang telah terealisasi : terlaksananya pemeliharaan rutin/berkala gedung kantor sebanyak 1 unit.

2. Rehabilitasi Sedang/Berat Rumah Dinas Rp. 400.000.000,Sasaran yang telah terealisasi : terlaksananya pemeliharaan rumah dinas yang nyaman dan layak yaitu rehab rumah dinas wakil bupati dan rehab rumah dinas eselon II.

3. Rehabilitasi Sedang/Berat Gedung Kantor Rp. 3.175.000.000,-

Sasaran yang telah terealisasi : terlaksananya gedung kantor hasil rehabilitasi/pembangunan yang siap pakai yaitu gedung pos silaut dan gedung kantor DPRD di Painan.

4. Pembangunan Sarana dan Prasarana Ibadah Rp. 3.700.000.000,-
Sasaran yang telah terealisasi : terlaksananya pembongkaran bangunan mesjid lama, pembangunan mesjid Agung Painan (lanjutan) dan penyiapan lahan RTH kawasan Mesjid Agung Painan.

b. Program Pengembangan dan Pengelolaan Jaringan Irigasi, Rawa dan Jaringan Pengairan Lainnya

Tujuan program adalah untuk mendukung tugas dan administrasi pemerintahan yang efektif dan efisien. Sasaran program adalah terbangunnya sarana air bersih pedesaan sebanyak 5 unit.

1. Pembangunan Infrastruktur Air Minum (DAK 2013) Rp. 1.600.841.000,-

Sasaran yang telah terealisasi : tersedianya jumlah pemanfaat air bersih yang diutamakan untuk masyarakat yang berdomisili di daerah lokasi pekerjaan yaitu : Infrastruktur Air Minum Silaut, Infrastruktur Air Minum Sei Gemuruh.

2. Pembangunan Infrastruktur Sanitasi (DAK 2013) Rp. 2.530. 979.000,-

Sasaran yang telah terealisasi : tersedianya Infrastruktur Sanitasi untuk masyarakat yang berpenghasilaan rendah dan berdomisili di tempat lokasi kegiatan yakni : Infrastruktur Sanitasi bayang Utara, Infrastruktur Sanitasi Sutera, Infrastruktur Sanitasi Linggo Sari Baganti.

c. Program Dukungan Dana Untuk Program Bersama (DDUPB)

Tujuan program untuk mendukung pelaksanaan penyelenggaraan kepemerintahan daerah kabupaten Pesisir Selatan agar efisien dan efektif. Sasaran program adalah tersedianya sumberdaya air dan infrastruktur 
perkotaan dan pedesaan sebanyak 18 Unit.

1. Pemb. Sistem Penyediaan Air Minum (SPAM) Ibu Kota Kecamatan (IKK) Salido Ketek Rp. 2.500.000.000,-

Sasaran yang telah terealisasi : terlaksananya pembangunan Sistem Penyediaan Air Minum (SPAM) Ibu Kota Kecamatan (IKK) Salido Ketek, dan Banpro Penyehatan PDAM.

2. Pemb. Sistem Penyediaan Air Minum (SPAM) Pangkalan Pendaratan Ikan (PPI) Rp. 750.000.000,-

Sasaran yang telah terealisasi : terlaksananya pembangunan Sistem Penyediaan Air Minum (SPAM) PPI Carocok Painan, SPAM PPI Batu Kalang Koto XI Tarusan, SPAM PPI Muaro Gadang Linggo Sari Baganti.

3. Pemb. Sistem Penyediaan Air Minum (SPAM) Masyarakat Berpenghasilan Rendah (MBR) Rp. 550.000.000,-

Sasaran yang telah terealisasi : terlaksananya pembangunan Sistem Penyediaan Air Minum (SPAM) MBR Punggasan Linggo Sari Baganti dan SPAM MBR Perkotaan Painan.

4. Pemb. Sistem Penyediaan Air Minum (SPAM) Kawasan Pesisir Rp. 1.050.000.000,-

Sasaran yang telah terealisasi : terlaksananya pembangunan Sistem Penyediaan Air Minum (SPAM) Kawasan Pesisir Pasir Pelangai, Kawasan Pesisir Nyiur Melambai, Kawasan Pesisir Sei. Tunu Barat.

5. Pemb. Sistem Penyediaan Air Minum (SPAM) Kawasan Desa Nelayan Rp. 800.000.000,-

Sasaran yang telah terealisasi : terlaksananya pembangunan
Sistem Penyediaan Air Minum (SPAM) Kawasan Desa Nelayan Batu Kalang Koto XI Tarusan, Kawasan Nelayan Muaro Gadang Linggo Sari Baganti, Kawasan Desa Amping Parak Sutera, Kawasan Desa Nelayan Koto Panjang Sutera.

6. Pembangunan Jalan BaliangBaliang Lanjutan Rp. 200.000.000,-

Sasaran yang telah terealisasi : terlaksananya Pembangunan Jalan Baliang-baliang Lanjutan.

7. Pembangunan Sarana dan Prasana Air Bersih Rp. 800.000.000,-

Sasaran yang telah terealisasi :

a. Terlaksananya pembangunan Sarana dan Prasarana Air Bersih Mandeh Terusan, Sapras Watermeter WTP, Sapras Air Bersih Kapuh (lanjutan).

b. Terlaksananya Rehabilitasi Intake di Batang Kapas

d. Program Pengendalian Pemanfaatan Ruang

Tujuan program untuk mendukung pelaksanaan penyelenggaraan kepemerintahan daerah kabupaten Pesisir Selatan agar efisien dan efektif. Sasaran program adalah terselenggaranya monitoring dan evaluasi terhadap tata bangunan di wilayah Kabupaten Pesisir Selatan.

1. Monitoring, Evaluasi dan Pelaporan untuk Pemetaan Kota Rp. 62.505.600,-

Sasaran yang telah terealisasi : terlaksananya monitoring, evaluasi dan pelaporan untuk pemetaan kota.

e. Program Monitoring, Evaluasi dan Pelaporan 
Tujuan program untuk mendukung pelaksanaan penyelenggaraan kepemerintahan daerah kabupaten Pesisir Selatan agar efisien dan efektif. Sasaran program adalah tersedianya pengawasan terhadap pembangunan rumah ibadah Mesjid Agung Painan.

1. Pengawasan Pembangunan Rumah Ibadah Rp. 40.000.000,Sasaran yang telah terealisasi : terlaksananya pengawasan terhadap pembangunan rumah ibadah Mesjid Agung di Painan.

\section{Program di Bidang Kebersihan dan Pertamanan}

a. Program Pembangunan Saluran

Drainase/Gorong-gorong

Tujuan program adalah untuk menukung tugas dan administrasi pemerintahan yang efektif dan efisien. Sasaran program adalah terbangunnya saluran drainase/gorong-gorong dan trotoar perkotaan.

1. Pembangunan Saluran Drainase / Gorong-gorong Rp. 340.000 .000

Sasaran yang telah terealisasi : terlaksananya pembangunan Saluran Drainase di Dinas Pekerjaan Umum, Drainase Pasar Air Haji, serta saluran drainase dan tembok penahanan sarana pengolahan sampah.

b. Program Pemeliharaan Sarana dan Prasarana Pertamanan

Tujuan program untuk mendukung pelaksanaan penyelenggaraan kepemerintahan daerah kabupaten Pesisir Selatan agar efisien dan efektif. Sasaran program adalah pemeliharaan sarana dan prasarana pertamanan.

1. Pemeliharaan dan Operasional Pertamanan Rp. 701.117.900,Sasaran yang telah terealisasi : terlaksananya pembuatan media tanam dan Pembangunan RTLH Shalter di Rawang Painan.
2. Pembangunan Sarana dan Prasarana Pertamanan Rp. 200.000.000,-

Sasaran yang telah terealisasi :

a. Tersedianya Sarana dan Prasarana di Sago.

b. Tersedianya Sarana dan Prasarana Bukit Putus (Gerbang Pintu Masuk Painan).

c. Program Pengendalian Pencemaran Lingkungan Hidup

Tujuan program untuk mendukung pelaksanaan penyelenggaraan kepemerintahan daerah kabupaten Pesisir Selatan agar efisien dan efektif. Sasaran program adalah pengendalian pencemaran lingkungan hidup.

1. Pengembangan Produksi Ramah Lingkungan Rp. 450. 721.000,Sasaran yang telah terealisasi : terlaksananya pemeliharaan TPA Gunung Bungkuk dan Perawatan Sarana IPLT.

2. Penunjang Pengolahan Sampah Terpadu 3 R Rp. 34.990.500,-

Sasaran yang telah terealisasi : tersedianya Penunjang Pengolahan Sampah Terpadu 3 R.

d. Program Pengembangan Kinerja dan Pengelolaan Persampahan

Tujuan program untuk mendukung pelaksanaan penyelenggaraan kepemerintahan daerah kabupaten Pesisir Selatan agar efisien dan efektif. Sasaran program adalah peningkatan sarana dan prasarana pengelolaan persampahan.

1. Penyediaan prasarana dan sarana Pengelolaan Persampahan Rp. 458.039.800,Sasaran yang telah terealisasi :

a. Terlaksananya pemeliharaan TPS permanen

b. Pengadaan bak kontainer 
c. Pembuatan WC portable

2. Peningkatan Operasi dan Pemeliharaan Prasarana dan Sarana Persampahan Rp. 850. 683. 320,-

Sasaran yang telah terealisasi : terlaksananya pemeliharaan prasarana dan sarana persampahan.

3. Pemeliharaan Rutin/berkala Kendaraan Operasional Kebersihan Rp. 786.162,500,-

Sasaran yang telah terealisasi : terlaksananya pemeliharaan rutin kendraan operasional kebersihan.

\section{SIMPULAN DAN SARAN}

Setelah melakukan analisis terhadap penyusunan Rencana Kerja Anggaran Satuan Kerja Perangkat Daerah (RKA-SKPD) Dinas Pekerjaan Umum Kabupaten Pesisir Selatan, maka dapat diambil kesimpulan sebagai berikut :

1. Rencana Kerja (Renja) Dinas Pekerjaan Umum Kabupaten Pesisir Selatan Tahun 2013 adalah penjabaran Rencana Strastegis (Renstra) Dinas Pekerjaan Umum Kabupaten Pesisir Selatan Tahun 2011-2015 dengan mengacu pada Rencana Pembangunan Jangka Menengah Daerah (RPJMD) Kabupaten Pesisir Selatan tahun 2011-2015 yang merupakan bahan acuan dan pedoman bagi pelaksanaan kegiatan Dinas Pekerjaan Umum Kabupaten Pesisir Selatan.

2. Dengan menggunakan analisis SWOT yaitu kekuatan (adanya peraturan-peraturan dan kebijakan kebijakan dari pemerintah yang mendukung kegiatan pembangunan, adanya hukum yang berlaku, sarana dan prasarana yang mendukung, pengawasan yang ketat terhadap pembangunan sehingga meningkatkan kualitas hasil pembangunan), kelemahan (terbatasnya dana APBD, Personil /SDM dirasakan kurang memadai, kurangnya partisipasi masyarakat terhadap pembangunan yang dilakukan, kurangnya koordinasi antar instansi terkait), peluang (adanya kesempatan pendidikan/Pelatihan/Diklat,

kemajuan teknologi di segala bidang), dan ancaman (bencana alam, unsur politik dan praktek KKN, masih banyaknya desa tertinggal), maka tersusunlah Rencana Kerja Anggaran (RKA) Dinas Pekerjaan Umum Kabupaten Pesisir Selatan yang sesuai dengan visi dan misi Dinas Pekerjaan Umum Kabupaten Pesisir Selatan.

3. Adapun visi dari Dinas Pekerjaan Umum Kabupaten Pesisir Selatan adalah " TERSEDIANYA INFRASTRUKTUR JALAN DAN PERMUKIMAN YANG ANDAL, UNTUK MENDUKUNG PESISIR SELATAN 2025"

4. Misi Dinas Pekerjaan Umum Kabupaten Pesisir Selatan :

a. Mewujudkan penataan ruang sebagai acuan mitra spesial dari pembangunan infrastruktur pekerjaan umum dan permukiman berbasis penataan ruang dalam rangka pembangunan berkelanjutan.

b. Meningkatkan kualitas lingkungan permukiman yang layak huni dan produksi melalui pembinaan dan fasilitas pengembangan infrastruktur permukiman yang terpadu andal dan berkelanjutan.

c. Menyelenggarakan dukungan manajemen fungsional dan sumberdaya yang akuntabel, 
kompeten, terinspirasi serta inovatif dengan menerapkan prinsip-prinsip good governance.

d. Meningkatkan aksebilitas dan mobilitas wilayah dalam mendukung pertumbuhan ekonomi dan meningkatkan kesejahteraan masyarakat dalam penyediaan jaringan jalan yang andal, terpadu, dan berkelanjutan.

e. Meminimalkan penyimpangan dan praktek-praktek KKN di lingkungan Dinas Pekerjaan Umum dengan meningkatkan kualitas pemeriksaan dan pengawasan profesional.

5. Penyusunan program dalam Rencana Kerja dan Anggaran Dinas Pekerjaan Umum sudah tepat pada sasarannya seperti :

a. Bidang Sekretariat

Program pelayanan administrasi perkantoran dengan sasaran tersedianya peralatan/perlengkapan untuk mendukung kegiatan administrasi perkantoran.

b. Bidang Bina Teknik

1. Program rehabilitasi/pemeliharaan jalan dan jembatan dengan sasaran tersedianya perencanaan terhadap rehabilitasi/pemeliharaan jalan dan jembatan.

2. Program pengembangan dan pengelolaan jaringan irigasi, rawa, dan jaringan pengairan lainnya dengan sasaran tersedianya perencanaan terhadap kegiatan sarana dan prasarana air bersih perkotaan pedesaan.

3. Program peningkatan sarana dan prasarana kebinamargaan dengan sasaran terpeliharanya alatalat labotarium kebinamargaan untuk mendukung kegiatan kebinamargaan.

c. Bidang Bina Marga

Program pembangunan jalan dan jembatan dengan sasaran terbangunnya jaringan jalan kabupaten dan jalan strategis serta jembatan pedesaan untuk membuka daerah terisolir.

d. Bidang Cipta Karya

1. Program peningkatan sarana dan prasarana aparatur dengan sasaran terpeliharanya bangunan pemerintah, dan sarana ibadah.

2. Program pengembangan dan pengelolaan jaringan irigasi, rawa dan jaringan pengairan lainnya dengan sasaran terbangunnya sarana dan prasarana air bersih.

e. Bidang Kebersihan dan Pertamanan

1. Program pemeliharaan sarana dan prasarana pertamanan dengan sasaran pemeliharaan sarana dan prasarana pertamanan.

2. Program pengendalian pencemaran lingkungan hidup dengan sasaran pengendalian pencemaran lingkungan hidup.

6. Dilihat dari penyusunan Rencana Kerja Anggaran yang dilakukan Dinas Pekerjaan Umum Kabupaten Pesisir Selatan, maka sudah terpenuhinya pembangunan daerah yang merata dan berkelanjutan untuk semua daerah di Kabupaten Pesisir Selatan.

7. Penelitian ini juga menguatkan penelitian sebelumnya yang 
dilakukan oleh Dewi (2012) dengan judul "Analisis Proses Penyusunan Anggaran Satuan Kerja Perangkat Daerah (RKA-SKPD) Dinas Pekerjaan Umum Kabupaten Deli Serdang dan Bangun Parlaungan Ritonga (2008) dengan judul "Proses Penyusunan Anggaran Satuan Kerja Perangkat Daerah (RKA-SKPD) BAPPEDA Kabupaten Tapanuli Selatan" yaitu penyusunan anggaran sudah sesuai dengan visi dan misi dari Dinas Pekerjaan Umum Kabupaten Deli Serdang dan BAPPEDA Kabupaten Tapanuli Selatan.

Mendukung pencapaian visi dan Kabupaten Pesisir Selatan sebaiknya kelemahan seperti terbatasnya dana APBD, Personil /SDM dirasakan kurang memadai, kurangnya partisipasi masyarakat terhadap pembangunan yang dilakukan, kurangnya koordinasi antar instansi terkait dan ancaman seperti bencana alam, unsur politik dan praktek KKN, masih banyaknya desa tertinggal harus segera diperbaiki dan disikapi.

\section{DAFTAR PUSTAKA}

Ananda, F., Putra, R. D. and Hendrastyo, V. S. (2017) 'Kesuksesan Implementasi System Application Product (SAP) studi kasus di PT. Semen Padang', Jurnal Pundi, 1(1), pp. 1-10. doi: 10.31575/jp.v1i1.4.

Ananda, F. and Zulvia, D. (2018) 'Indikasi machiavellianism dalam pembuatan keputusan etis auditor pemula', Benefita, 3(September), pp. 357-369. doi: 10.22216/jbe.v3i3.3660.
Arifin Sabeni,dkk.2001.Pokok-pokok Akuntansi

Pemerintahan, Yogyakarta:BP FE-Yogyakarta.

Bastian,Indra, 2001. Akuntansi Sektor Publik di Indonesia, BPFEYogyakarta, Yogyakarta.

David, Fred, R, 2006, Manajemen Strategi, Salemba Empat, Jakarta.

Dewi.2012. Proses Penyusunan Anggaran Satuan Kerja Perangkat Daerah (RKASKPD) Dinas Pekerjaan Umum Kabupaten Deli Serdang. (Skripsi). Universitas Sumatera Utara.

Mardiasmo, 2002. Akuntansi Sektor Publik, Andi Yogyakarta, Yogyakarta.

Menteri Dalam Negeri, Keputusan Menteri dalam Negeri Nomor 13 Tahun 2006, Tentang Pedoman Pengelolaan Keuangan Daerah.

Menteri Dalam Negeri, Keputusan Menteri dalam Negeri Nomor 54 Tahun 2010, Pelaksanaan Peraturan Pemerintah Nomor 8 Tahun 2008 tentang Tahapan, Tatacara Penyusunan, Pengendalian, dan Evaluasi Pelaksanaan Rencana Pembangunan Daerah.

Nordiawan, Deddi, 2005. Akuntansi Sektor Publik, Salemba Empat, Jakarta. 
Nordiawan, Deddi, 2006. Akuntansi Sektor Publik, Salemba Empat, Jakarta.

Presiden Republik Indonesia.Peraturan Pemerintah Republik Indonesia Nomor 25, 2000, Kewenangan Pemerintah dan Kewenangan Provinsi Sebagai Daerah Otonom.

Presiden Republik Indonesia.Peraturan Pemerintah Republik Indonesia Nomor 108, 2000, Tatacara

Pertanggungjawaban Kepala Daerah.

Presiden Republik Indonesia.Peraturan Pemerintah Republik Indonesia Nomor 58, 2005, Pengelolaan Keuangan Daerah.

Ritonga, Parlaungan, Bangun. 2008. Proses Penyusunan Anggaran Satuan Kerja Perangkat Daerah (RKA-SKPD) Badan Perencanaan Pembangunan
Daerah Pemerintah

Kabupaten Tapanuli Selatan. (Skripsi). Universitas Sumatera Utara.

Sony Yuwono, Tengku Agus Indrajaya, Hariyandi, 2005. Penganggaran Sektor Publik, Bayumedia, Malang.

Sony Yuwono, Tengku Agus Indrajaya, Hariyandi, 2006. Penganggaran Sektor Publik, Bayumedia, Malang.

Undang-undang Nomor 17 Tahun 2003 tentang Keuangan Negara.

Undang-undang Nomor 32 tahun 2004 tentang Pemerintah Daerah.

Undang-undang Nomor 33 tahun 2004 tentang Perimbangan Keuangan antara Pemerintah Pusat dengan Pemerintah Daerah.

Yodi Haya, 2008, Worshop Reformasi Pengelolaan Keuangan Daerah. 